\title{
Prehistoric dangers and contemporary prejudices
}

\author{
Mark Schaller, Justin H. Park and Jason Faulkner \\ University of British Columbia, Canada
}

\begin{abstract}
We review the logical principles that guide the application of evolutionary ideas to psychological problems, and show how these principles can be used to derive novel, testable hypotheses about contemporary prejudice processes. We summarise two recent lines of research employing this approach. One line of research examines prejudices resulting from perceived vulnerability to physical injury. The other examines prejudices resulting from perceived vulnerability to disease. Results from both lines of research support novel psychological hypotheses identifying variables - pertaining to both personality and to local context - that trigger specific prejudices against specific categories of people. We conclude by discussing more broadly some of the useful conceptual and practical implications of this evolutionary approach to prejudice.
\end{abstract}

\begin{abstract}
"We humans have to grant the presence of some past adaptations, even in their unforgivable extremes, if only to admit they are permanent rocks in the stream we're obliged to navigate."
\end{abstract}

(Barbara Kingsolver, 1995, p. 8)

The psychological study of prejudice is often motivated not only by scientific goals, but by practical social goals as well. If we can better understand the causes and processes of prejudice, then we might be better prepared to navigate our way around the problems that prejudices pose. And, ideally, we might be able to devise interventions that inhibit the prevalence of these problems.

Consistent with these goals, there are numerous examples of specific ways in which inquiry into the processes that underlie prejudice has led to the development of intervention strategies that actually have some

Correspondence should be addressed to Mark Schaller, Department of Psychology, University of British Columbia, 2136 West Mall, Vancouver, BC V6T 1Z4, Canada, Email: schaller@psych.ubc.ca.

The research reported in this article was supported by a grant from the Social Sciences and Humanities Research Council of Canada, and by a fellowship from the Natural Sciences and Engineering Research Council of Canada.

(C) 2003 Psychology Press Ltd

http://www.tandf.co.uk/journals/pp/02699931.html

DOI: $10.1080 / 10463280340000036$ 
positive impact (e.g., Gaertner \& Dovidio, 2000; Schaller, Asp, Rosell, \& Heim, 1996; Wright, Aron, McLaughlin-Volpe, \& Ropp, 1997). For example, the study of social identity processes has led to interventions based on the creation of common ingroup identities, and these interventions can help to reduce intergroup prejudices and conflict (Gaertner, Dovidio, Anastasio, Bachman, \& Rust, 1993). These results are encouraging.

But we must be careful not to overgeneralise the practical utility of these sorts of results. In the social psychological laboratory, where it is possible to create stereotypes and prejudices quite quickly, it is also possible to eliminate them more easily than we can in the real world where prejudices often have longer histories and deeper roots. The fracturing of the former Yugoslavia along ethnic and cultural lines reveals, among other things, that deeply held prejudices may not be so easily eliminated by common superordinate identities even when those identities persist across a lifetime or longer. This example does not diminish the importance of social identity processes in our understanding of intergroup prejudice, but it does suggest that many other processes are important as well. If we are to truly understand the prejudices that exist in the world around us - and if we hope to be able to do something about them-then we must be prepared to discover and intellectually embrace any and all of the processes that might contribute to those prejudices.

Our purpose here is to illustrate the utility of applying the tools of evolutionary psychology towards that goal. When applied rigorously, informed speculations about evolutionary prehistory can lead to hypotheses about contemporary prejudice processes - including hypotheses that specify which individuals are especially likely to be prejudiced, circumstances under which individuals are especially likely to be prejudiced, and categories of individuals that are especially likely to become targets of these particular prejudices. While the underlying evolutionary speculations are difficult to verify, the resulting psychological hypotheses can be tested directly with standard research methods. Consequently, this meta-theoretical approach provides a useful means of making novel discoveries about contemporary prejudice processes.

For several different reasons, people are sometimes uncomfortable with evolutionary approaches to prejudice. Some of these reasons are rooted in common misunderstandings about what an evolutionary approach does and does not logically imply when applied to complex psychological phenomena such as prejudice. Therefore, we begin by reviewing the logic that guides the application of evolutionary principles to contemporary prejudice processes. We then describe two recent lines of research informed by this evolutionary logic. These lines of research have identified and supported novel hypotheses about variables that trigger the experience and expression of specific 
prejudices. We conclude by discussing more broadly some of the useful implications of this evolutionary approach to prejudice.

\section{EVOLUTIONARY PRESSURES AND PSYCHOLOGICAL RESPONSES}

\section{Evolutionary psychology as a tool for conceptual discovery}

Evolutionary processes operate on populations over very long periods of time, while psychological processes operate on individuals at very specific points in time. These two sets of processes comprise two very different levels of scientific analysis. In recent years, there have been substantial advances in understanding the complex linkages between evolutionary processes and the psychological processes governing the thoughts, emotions, and actions of individuals (Barkow, Cosmides, \& Tooby, 1992; Buss, 1995; Crawford \& Krebs, 1998; Cummins \& Allen, 1998; Gangestad \& Simpson, 2000; Marr, 1982; Pinker, 1997; Scher \& Rauscher, 2002; Simpson \& Kenrick, 1997). These lines of inquiry have revealed clearly defined logical strategies for the application of evolutionary principles towards the development of testable theories about psychological processes.

It is easy to engage in a sort of "backward-thinking" approach to evolutionary psychology - to make up plausible evolutionary scenarios that might explain the origins of phenomena that have already been observed in contemporary human environments. But to be useful to psychological scientists, evolutionary psychology must do more than simply explain the historical origins of existing phenomena; it must produce novel hypotheses pertaining to psychological processes in the here-and-now (Conway \& Schaller, 2002; Ketelaar \& Ellis, 2000). It is therefore necessary to apply a more "forward-thinking" deductive approach (Murphy, 2003). This approach begins with the specification of well-articulated assumptions about specific problems pertaining to survival and/or sexual reproduction that plausibly existed in the evolutionary past. Because specific problems imposed specific selection pressures on ancestral populations, it is then possible to deduce hypotheses about psychological mechanisms that might have evolved in response to those pressures. These hypotheses about evolutionary processes in the past can, in turn, be used to derive hypotheses about psychological responses that may still operate in the present. Hypotheses derived in this manner are logically no different from any other psychological hypotheses, and they can be tested with the methods of experimental psychology. The evolutionary background adds to the richness of the theoretical structures from which these hypotheses are derived, but the primary value of this meta-theoretical approach ultimately lies in the 
specification and empirical testing of these evolutionarily informed hypotheses: These tests can lead to novel empirical discoveries about contemporary human cognition and behaviour.

\section{Characteristics of evolved psychological processes}

An essential element in most evolutionary approaches to psychology is the assumption that a specific psychological process served some useful function to individuals in ancestral times. Thus, if fear has an evolutionary basis (and it appears that it does; see Öhman \& Mineka, 2001, for an extensive discussion), it is because the capacity for fear served an important function during a vast period of human evolutionary history. (It is not the case, however, that evolved responses are necessarily functional in contemporary contexts. The mechanisms of biological evolution proceed much more slowly than cultural change, and psychological mechanisms that evolved in response to ancestral environments may be counter-productive in many contemporary environments.)

The functional logic of evolutionary psychology typically leads to the specification of pan-human psychological mechanisms. These universal mechanisms pertain primarily to the basic psychological structures through which information is perceived and processed, and through which cognitive, affective, and behavioural "outputs" are generated. For example, in general, people have the capacity to experience fear when they perceive information indicating the proximity of some imminent danger. Rarely, however, does the specification of these universal mechanisms imply equivalence across individuals in psychological outputs. There are vast individual differences in fear responses (e.g., some people are more chronically fearful than others) that result from the many additional, more proximal, influences on individual information processing. These influences include additional biological processes that promote genetic diversity within human populations, as well as the effects of local environments and social learning processes. (Individual differences are not irrelevant to evolutionary psychology, however. Regardless of their origin, many individual difference variables can serve as perceptual inputs that influence the operation of evolved psychological processes. We discuss this point at greater length below.)

As with other psychological processes, evolved psychological processes are highly flexible. Most of these processes (particularly those of most relevance to the study of social cognition) provide for the capacity to respond in specific ways to specific categories of perceptual input. Thus, the evolved mechanisms underlying fear provide the capacity for a fear response to be triggered in response to specific perceptual cues (such as an unexpected loud noise) that appear to indicate the proximity of some imminent danger. 
The process whereby individuals respond to perceptual cues provides one of several points at which social learning mechanisms intersect importantly with evolved psychological mechanisms. While there may be an evolved, pan-human tendency to respond with fear to cues connoting imminent danger, individuals must learn many of the specific stimulus cues that connote danger (Öhman \& Mineka, 2001). There may be innate predispositions to quickly learn certain kinds of stimulus-response linkages (see Garcia, 1981, for discussion of one classic example), but other linkages may be based more fully on learning processes. Consequently, even for psychological processes that very clearly have some basis in evolutionary biology - such as those pertaining to human emotions - there may be differences between individuals, and between cultures, in the sets of cues that trigger these processes (Park, Faulkner, \& Schaller, 2003).

The engagement of adaptive responses often conforms loosely to some sort of implicit cost-benefit analysis (if cues indicate the presence of some dangerous thing, then the costs associated with a fear response are likely to be outweighed by the benefits precipitated by that response), but this does not mean that they are engaged only after rational consideration. Often these psychological responses are reflexive-triggered spontaneously and automatically by the simple perception of cues (Schaller, 2003). The automaticity of the fear response is such that a fear response may be triggered by a perceptual cue (e.g., loud noise) even when the perceiver is explicitly aware that no danger is present. Consequently, these processes are fallible (Haselton \& Buss, 2000). Because many evolved psychological processes respond reflexively to heuristic cues, they may be triggered under circumstances in which, from a rational perspective, they serve no real function.

Because evolved psychological mechanisms are responsive to information that informs an implicit cost-benefit analysis, the strength of association between eliciting stimulus and adaptive response may be moderated by additional "background" variables that bear on that implicit-and fallible - cost-benefit analysis. Thus, stimuli that typically elicit fear may elicit more fear when individuals already feel especially vulnerable to harm, and may elicit less fear when they feel personally invulnerable. Some of this background information may be provided by chronic individual difference variables. Individuals who are generally more fearful and wary of dangerfor whatever reason-are likely to have a lower threshold for the "triggering" of the evolved mechanisms whereby fear is elicited in response to some perceptual cue (such as a loud noise). Many evolutionary psychological theories yield hypotheses implying relations between specific individual difference variables and the strength of specific psychological responses (e.g., Gangestad \& Simpson, 2000).

Other background information is provided by temporary contextual cues that connote the potential costs or benefits of response. A fearful reaction to 
loud noises, for example, is especially pronounced under conditions of ambient darkness, a contextual cue that heuristically connotes vulnerability to harm (Grillon, Pellowshi, Merikangas, \& Davis, 1997). Many evolutionary psychological theories yield hypotheses implying causal effects of specific environmental and social contexts on the strength of specific psychological responses (e.g., Burnstein, Crandall, \& Kitayama, 1994).

\section{EVOLUTIONARY MODELS OF CONTEMPORARY PREJUDICE PROCESSES}

In recent years, a number of theoretical models have suggested ways in which contemporary group stereotypes and prejudices may be consequences of psychological mechanisms that evolved a long time ago (Fox, 1992; Krebs \& Denton, 1997; Kurzban \& Leary, 2001; Neuberg, Smith, \& Asher, 2000; Schaller, 2003). The common evolutionary logic underlying these perspectives is summarised by Kurzban and Leary (2001): The contemporary human mind evolved in response to the adaptive problems imposed by the environments in which ancestral populations lived; for the past several million years of this evolutionary history, ancestral populations lived in social groups; specific adaptive problems associated with group life may have given rise to specific psychological mechanisms that influenced evaluative perceptions of and reactions to individuals associated with specific sorts of groups. In other words, certain prejudicial ways of thinking and acting may have conferred adaptive benefits within ancestral environments, and now-even though contemporary environments are very different in very many ways - those prejudicial ways of thinking and acting may persist.

Within this broad evolutionary framework, there are a number of conceptually distinct theoretical models identifying links between specific adaptive problems of the past and specific prejudice processes in the present. For instance, one model links the adaptive utility of status hierarchies with contemporary tendencies to express domination over others (Pratto, Sidanius, \& Stallworth, 1993). Another model links the adaptive utility of cooperative social exchange behaviours with contemporary prejudices against individuals who, either because of disinclination or disability, tend to contribute fewer resources than they receive (Kurzban \& Leary, 2001; Neuberg et al., 2000). These theoretical models add a level of historical depth and richness to our understanding of well-known prejudice phenomena. More importantly, though, these evolutionary analyses are beginning to yield novel answers to questions that are not easily addressed by other models of prejudice. For instance, Neuberg and Cottrell (2002) draw on evolutionary logic to make predictions - supported by empirical data-about the specific affective contents of negative attitudes towards 
different outgroups. The results reveal that prejudices that appear identical in terms of overall evaluative valence are in fact qualitatively distinct in predictable ways. This research highlights important, under-researched questions about the specific contents of prejudices, and provides answers to these questions through the deduction of novel hypotheses.

In our own recent research, we have focused on two specific evolutionarily informed models of prejudice processes, each of which yields novel predictions about the specific variables that trigger specific prejudices against specific peoples. One of these processes focuses on vulnerability to physical injury. The other focuses on vulnerability to disease. In the sections that follow, we describe the evolutionary logic underlying these models and summarise some of the recent empirical evidence supporting novel psychological hypotheses derived from each model.

\section{PERCEIVED VULNERABILITY TO PHYSICAL INJURY AND ITS EFFECTS ON PREJUDICE}

For sensible reasons, we are wary around others who pose some real danger of inflicting physical injury upon us, and we harbour negative attitudes towards exactly these sorts of people. Less rationally, however, it appears that perceived vulnerability to physical injury may be linked to prejudices against categories of people who do not pose any objective danger or threat, and that these prejudices may be moderated by cues that heuristically connote increased (or decreased) vulnerability.

\section{Conceptual background}

The conceptual logic underlying this linkage is summarised within a theoretical structure that we have been calling "intergroup vigilance theory". The key assumption underlying this theory pertains to a specific evolutionary pressure operating on populations during that long stretch of evolutionary history in which individuals lived in small tribal units. Within this tribal context, there may have been real physical risks associated with unexpected interactions with "outsiders" - strangers who were not part of the tribal ingroup. Cognitive structures that motivated the vigilant avoidance of potentially injurious intergroup encounters would have been adaptive. Consequently, innate psychological mechanisms may have emerged that facilitated the learning and consequent activation of cognitive associations linking tribal outsider status with expectations of dangerous intent. Given reciprocal relations between cognition and culture (Kenrick, Li, \& Butner, 2003; Schaller \& Crandall, 2003), these cognitive mechanisms are likely to have an impact on-and in turn to be supported by-the emergence of specific kinds of cultural 
norms, such as myths and legends illustrating the dangers posed by strange peoples.

The cognitive association linking outsiders with danger is expected to be responsive to perceptual cues (facial features, linguistic labels, etc.) that connote "tribal" outgroup status. The exact nature of these cues may vary, of course, depending on local cultural conditions and learning environments. In many contemporary cultural contexts, cues clearly connoting ethnic and/or national outgroup status may trigger the activation of cognitions indicating dangerous intent.

The activation of these cognitions (along with an associated fearful response) is expected to be moderated by additional background variablesincluding both chronic individual differences and temporary circumstances - that heuristically indicate functional costs or benefits of responding in a prejudicial manner. Especially relevant are variables connoting personal vulnerability to harm (e.g., a high likelihood of unexpected and potentially dangerous intergroup contact). Individuals who chronically feel vulnerable to harm are especially likely to perceive tribal outgroups as dangerous. In addition, this specific prejudicial perception of outgroups is likely to be facilitated under temporary circumstances that connote personal vulnerability. The operation of an implicit cost-benefit analysis also implies that there may be interactive effects among multiple background variables. For example, the facilitating effects of any one variable may be muted if another variable clearly connotes safety and invulnerability, whereas the facilitating effects may be strengthened if another variable indicates the need for wariness.

\section{Implications and empirical evidence}

On the basis of this analysis, intergroup vigilance theory yields a number of implications and predictions about the specific nature of intergroup prejudice, and the moderators of that prejudice.

One implication is that individuals who are perceived to be outsidersmembers of outgroups that fit a tribal template - inspire the sort of threatrelated emotional and cognitive reactions that typically motivate vigilant avoidance. Empirical research bears this out. Encounters with members of ethnic outgroups are associated with self-reported and physiological indicators of fear and anxiety (Blascovich, Mendes, Hunter, Lickel, \& Kowai-Bell, 2001; Phelps et al., 2000). Ethnic outgroups also inspire negative stereotypes and attitudes consistent with those emotional responses (Phelps et al., 2000; Stephan, Diaz-Loving, \& Duran, 2000; Stephan, Ybarra, Marinez, Schwarzwald, \& Tur-Kaspa, 1988).

A second implication is that these kinds of prejudicial responses are likely to be especially strong among individuals who feel chronically 
vulnerable to interpersonal danger. Altemeyer (1988) developed a useful self-report questionnaire assessing individual differences in "belief in a dangerous world" (BDW). The BDW scale includes 12 items of the following sort: "There are many dangerous people in our society who will attack someone out of pure meanness, for no reason at all" and "Despite what one hears about 'crime on the street,' there probably isn't any more now than there ever has been". The items all pertain to perceptions of interpersonal danger in general; not a single item pertains specifically to perceptions of outgroups. Nevertheless, Altemeyer (1988) found that individuals with higher levels of BDW also expressed higher levels of prejudice against outgroups.

It is worth noting that the internally coherent BDW scale correlates substantially with measures designed to assess the multiple psychological constructs that comprise "the authoritarian personality" (Adorno, FrenkelBrunswik, Levinson, \& Sanford, 1950; Altemeyer, 1988). This may help us understand better why authoritarianism predicts prejudice. At a psychologically fundamental level, the effect may be based not so much on political ideology, beliefs about authority, or cognitive rigidity - all of which are conceptually distinct facets of the authoritarian personality style-but on an irrational feeling of vulnerability to danger. Suedfeld and Schaller (2002) have argued that it is this particular fear-based facet of authoritarianism that is most useful in understanding the complicated relationship between authoritarianism and complicity in extreme acts of prejudice, such as genocide.

A third implication is that prejudicial responses are likely to be facilitated by transient cues connoting increased vulnerability to harmful encounters with outgroups. Some of these contextual variables are obvious. For instance, stereotypical associations with danger and prejudicial beliefs are expected to be magnified by information indicating increased likelihood of intergroup conflict or competition. This clearly is the case. Information connoting intergroup conflict leads stereotypic beliefs to coalesce around danger-relevant characteristics and images (Alexander, Brewer, \& Herrmann, 1999). Information connoting conflict or threat leads individuals to perceive outgroups as more stereotypically homogeneous (Judd \& Park, 1988; Rothgerber, 1997), and amplifies tendencies toward ingroup favouritism and outgroup derogation (Brewer, 1979).

Other background variables may more indirectly connote a heightened risk of potentially injurious intergroup contact. The relative size of ingroup and outgroup is one such variable. The greater the relative size of an outgroup, the more vulnerable individuals are to an injurious inter-group encounter. Consistent with this reasoning, there is considerable evidence that the increased size of an outgroup is associated with increased prejudice (Mullen, Brown, \& Smith, 1992). 


\section{4}

Perhaps more interestingly, intergroup vigilance theory implies that the same sorts of prejudicial consequences may also be influenced by other danger-connoting contextual variables, even if those variables are logically irrelevant to groups or intergroup relations. This follows from the assertion that these evolutionarily influenced prejudice processes are facilitated by any kind of background information that heuristically connotes personal vulnerability to harm (even if, rationally, one recognises that there is no danger of harmful intergroup encounter). One such a cue is ambient darkness. We recently conducted a series of studies examining the causal effects of ambient darkness on the activation of content-specific prejudicial beliefs. These studies provide particularly strong tests of hypotheses derived from intergroup vigilance theory. In addition, because no previous theory or research has linked ambient darkness to the psychology of prejudice, these studies illustrate the value of this theory as a tool for the discovery of novel phenomena.

\section{Study 1: Effects of ambient darkness on prejudicial trait ratings}

The onset of darkness can arouse anxiety and fear. This makes considerable adaptive sense given that in darkness there is a diminution of visual information - a major liability for a species that relies heavily on vision to navigate physical and social landscapes and to avoid dangers lurking within those landscapes. Thus, whereas ambient light may be reassuring, the onset of darkness may serve as a heuristic cue indicating vulnerability to physical danger (Grillon et al., 1997). As a result, ambient darkness may lead individuals to be especially wary of potential dangers implicitly associated with ethnic outgroups.

A preliminary test of the impact of ambient darkness on intergroup prejudice emerged from the results of a very simple pilot study conducted in 1998. Participants were 17 high-school students from Vancouver, British Columbia (Canada). Participants were assigned to one of two experimental sessions; one session comprised the Light condition, and the other comprised the Dark condition. In both conditions, participants were seated in a windowless room, and given blank sheets of paper on which they were instructed to write down answers to a brief set of questions that they were asked by the experimenter. Participants were asked to rate "people from Iraq" and "people from Canada" on four trait dimensions (hostile, ignorant, trustworthy, open-minded); each rating was made by writing down a number from 1 to 10 on the blank sheet of paper. In the Light condition, the experimenter simply proceeded to recite the questions to which participants recorded their responses on the blank sheets of paper. In the Dark condition, immediately prior to reciting the questions, the experimenter 
turned off the lights that had been illuminating the room (participants were informed that they would be given an explanation at the conclusion of the study). These participants listened to the questions and recorded their responses in the dark. They had no difficulty in making legible rating responses, even though they could not see the paper on which they were writing.

Based on prior research (Rothbart \& Park, 1986) and our own pretesting, we determined that two of these traits (hostile, ignorant) were approximately equally negatively valenced, but differed in the extent to which they connoted danger. The two other traits (trustworthy, openminded) were approximately equally positively valenced but also differed in danger-relevance. Consequently, after reverse-scoring ratings on the negatively valenced traits, we computed separate two-item composite indices indicating evaluations of ingroup and outgroup on (a) traits high in danger-relevance, and (b) traits low in danger-relevance. (Table 1 summarises these means.) We then subtracted ratings of the outgroup from the ingroup, to create two measures of ingroup favouritism - one indicating ingroup favouritism on high danger-relevance traits, and the other indicating ingroup favouritism on low danger-relevance traits. Figure 1 depicts the degree of ingroup favouritism that emerged on each index, separately within the Light and Dark experimental sessions. On highly danger-relevant traits, ingroup favouritism was higher in the dark than in the light, but no such difference was observed on low danger-relevance traits. Results from a $2 \times 2$ repeated measures ANOVA indicate that, despite the small sample size, sampling error cannot readily account for any such Darkness $\times$ Index interaction, $F(1,15)=3.38, p=.086$. Note that this

TABLE 1

Effects of darkness on evaluations of ingroup and outgroup (Study 1)

\begin{tabular}{llcc}
\hline & & Light & Dark \\
\hline $\begin{array}{l}\text { High danger-relevance traits } \\
\text { Rating of ingroup }\end{array}$ & Mean & 6.95 & \\
& (SD) & $(1.30)$ & $(1.36$ \\
Rating of outgroup & Mean & 5.35 & 4.65 \\
& (SD) & $(1.20)$ & $(1.22)$ \\
Low danger-relevance traits & & & \\
Rating of ingroup & Mean & 6.15 & 6.79 \\
Rating of outgroup & (SD) & $(1.13)$ & $(1.29)$ \\
& Mean & 4.85 & 5.61 \\
& (SD) & $(1.13)$ & $(1.66)$ \\
\hline
\end{tabular}

Ratings of ingroup and outgroup are scaled in such a way that higher values indicate more favourable evaluations. 


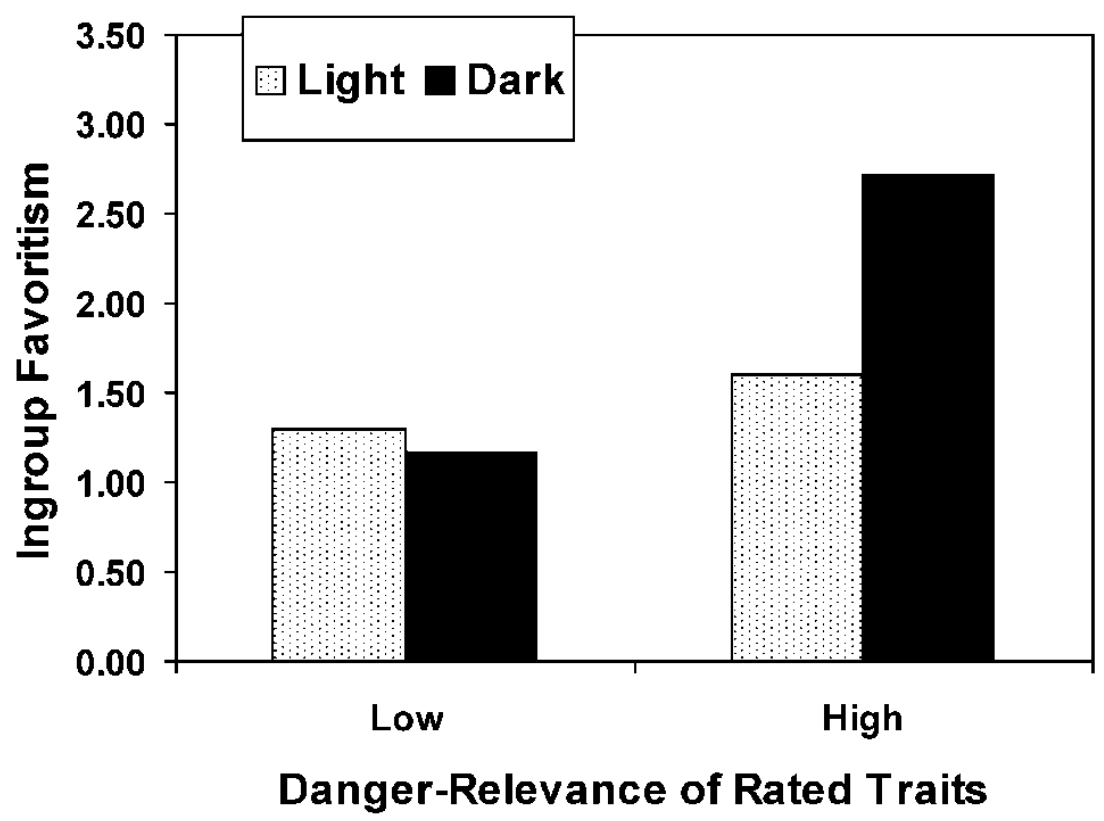

Figure 1. Effect of ambient darkness on ingroup favouritism reflected in trait ratings (Study 1).

probability value is based on a non-directional test of the null hypothesis, and so is conservative; the likelihood is lower that sampling error alone could produce the specific interaction predicted and observed here, $p=.043$.

\section{Study 2: Interactive effects of darkness and "belief in a dangerous world" on prejudicial trait ratings}

Before drawing conclusions from the results of that preliminary study, it is important to consider also the results from an additional study with similar methods. This study (conducted in 1999) was more rigorous, and also tested the moderating effect of an additional background variable. Specifically, this study examined the interactive effects of ambient darkness and beliefs in a dangerous world. The rationale follows from intergroup vigilance theory: Among individuals who chronically worry that harm might befall them, ambient darkness may be especially likely to facilitate the activation and expression of prejudicial beliefs (particularly beliefs about dangerous intent). But among individuals who chronically feel safe from harm, the effects of darkness may be muted.

The procedures were similar to those described above. Participants were 69 students from the University of British Columbia. Several participants at 
a time participated in each experimental session, through which they were randomly assigned to either the Light condition or the Dark condition. Participants sat in a windowless room that was well-lit by electric fluorescent lights, and completed several questionnaires, including the "belief in a dangerous world" questionnaire described above (BDW; Cronbach's alpha in this sample was .81).

Participants were then given blank sheets of paper and instructions on how to record their ratings on these sheets. The experimenter explained that future instructions and questions would be provided by a pre-recorded voice on audiotape. The experimenter then turned on the audiotape player. After the voice on the tape gave a few preparatory instructions, the experimenter paused the audiotape and ascertained that the voice was audible to all participants.

In the Light condition, the experimenter restarted the audiotape and further instructions were provided by the voice on tape.

In the Dark condition, the experimenter followed the same procedures, with one exception: Just prior to restarting the audiotape (and after announcing to participants that they would be given an explanation later) the experimenter turned off the lights that had been illuminating the room. The participants listened to the audiotaped instructions and recorded their ratings in the dark.

Participants were asked to rate "men from Iraq" and "men from Canada" on four trait dimensions (hostile, ignorant, trustworthy, openminded) by writing down a number from 1 to 10 . In addition-as a global measure of perceived intra-group homogeneity - they also rated how similar to each other Iraqis are, and how similar to each other Canadians are. (As in Study 1, participants had no difficulty recording legible ratings, even in the Dark condition in which they could not see the paper on which they were writing.)

Following the same computational procedures used in Study 1, we computed composite indices reflecting the ratings of Canadians and Iraqis on low and high danger-relevance traits. (Table 2 summarises mean ratings on these two indices, broken down according to whether participants scored low or high on BDW-based on a median split for illustrative purposes - and whether they participated in the Light or Dark condition.) These values were then used to compute two indices of ingroup favouritism: One index assessed ingroup favouritism on highly danger-relevant traits; the other assessed ingroup favouritism on low danger-relevance traits.

The effects of BDW and Darkness on each of these two indices were tested with regression analyses. Darkness and BDW were first transformed into $z$-scores. The multiplicative product of these two $z$-scores was computed, representing the BDW $\times$ Darkness interaction. The standardised 
TABLE 2

Interactive effects of darkness and belief in a dangerous world (BDW) on evaluations of ingroup and outgroup (Study 2)

\begin{tabular}{lllllll}
\hline & & \multicolumn{2}{c}{ Low BDW } & & \multicolumn{2}{c}{ High BDW } \\
& & Light & Dark & & Light & Dark \\
\hline High danger-relevance traits & & & & & & \\
Rating of ingroup & Mean & 7.08 & 6.88 & & 6.68 & 7.18 \\
& (SD) & $(1.10)$ & $(1.34)$ & & $(1.32)$ & $(1.13)$ \\
Rating of outgroup & Mean & 5.17 & 5.79 & & 4.97 & 3.94 \\
& (SD) & $(1.69)$ & $(1.70)$ & & $(1.52)$ & $(1.47)$ \\
& & & & & & \\
Low danger-relevance traits & & & & & & \\
Rating of ingroup & Mean & 7.31 & 7.00 & & 5.68 & 6.91 \\
& (SD) & $(1.26)$ & $(1.49)$ & & $(1.40)$ & $(1.29)$ \\
Rating of outgroup & Mean & 5.42 & 5.12 & & 4.00 & 5.00 \\
& (SD) & $(1.81)$ & $(1.36)$ & & $(1.52)$ & $(1.15)$ \\
\hline
\end{tabular}

Ratings of ingroup and outgroup are scaled in such a way that higher values indicate more favourable evaluations.

BDW and Darkness variables and the interaction variable were entered as predictors in a pair of regression analyses. There were no meaningful effects on the low danger-relevance index. In contrast, effects did emerge on the high danger-relevance index of ingroup favouritism. There was a main effect of BDW (beta $=.27, p=.019)$, and this main effect was qualified by a $\mathrm{BDW} \times$ Darkness interaction (beta $=.31, p=.008)$. There was essentially no relation between BDW and danger-relevant ingroup favouritism in the Light $(r=-.03)$, but there was a substantial relation in the Dark $(r=-.56)$. A different depiction of the interaction is provided in Figure 2 (in which, strictly for the sake of illustration, high- and low-BDW categories were based on a median split). This figure reveals that darkness facilitated ingroup favouritism (on highly danger-relevant traits) among high-BDW individuals, but not among low-BDW individuals.

There were no meaningful effects of BDW and Darkness on rated similarity within the ingroup, but there was some evidence of an interactive effect on ratings of within-outgroup similarity. The rating of similarity among Iraqis was entered as a dependent variable in a regression analysis following the same format as those described above. Three predictor variables were included, representing the main and interactive effects of BDW and Darkness. The result of greatest interest was a weak, but potentially meaningful, BDW $\times$ Darkness interaction effect $($ Beta $=.20, \quad p=.095$; this probability value is based on a conservative, non-directional test of the null hypothesis; a directional 


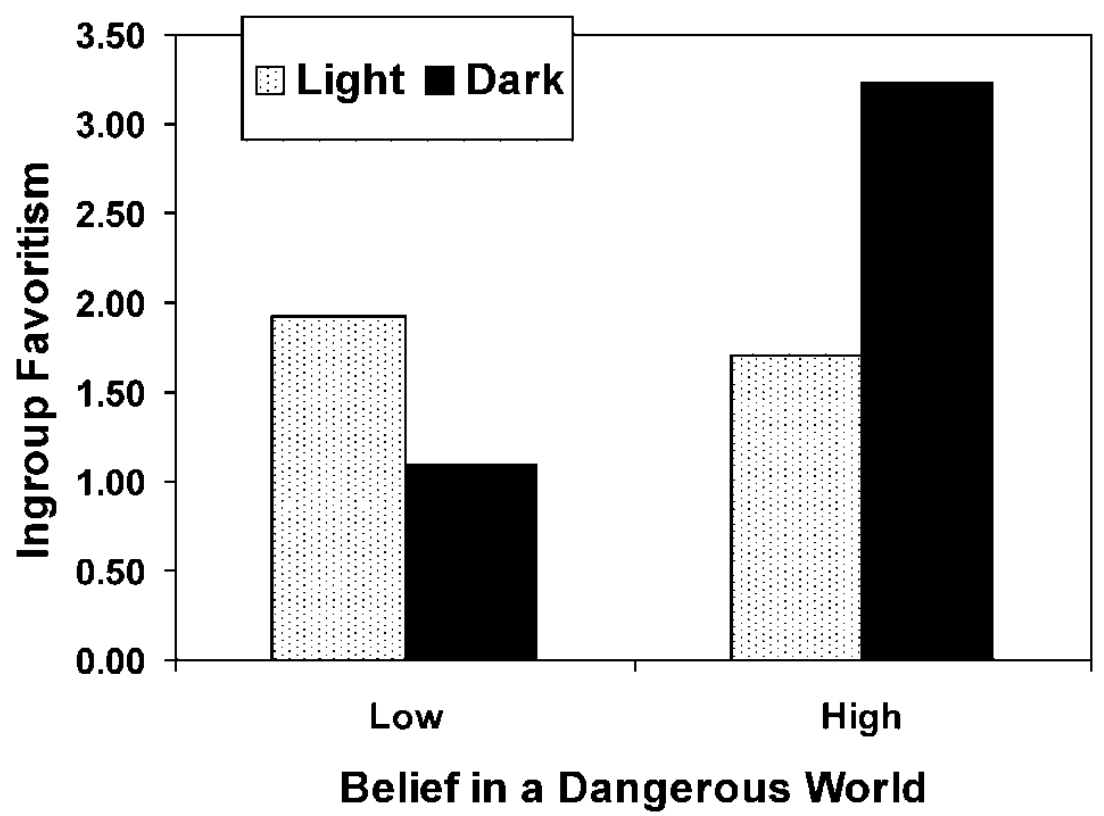

Figure 2. Interactive effect of ambient darkness and belief in a dangerous world on ingroup favouritism reflected in ratings on highly danger-relevant traits (Study 2).

test yields $p=.048$ ). Deeper examination of this effect revealed that BDW predicted ratings of within-outgroup similarity in the Dark $(r=.39$, $p=.021)$ but not in the Light $(r=.01)$. A different depiction of the interaction is provided in Figure 3 (in which, strictly for the sake of illustration, high- and low-BDW categories were based on a median split). This figure reveals that among high-BDW individuals-but not low-BDW individuals - darkness led to greater perceived homogeneity within the outgroup.

Results illustrated in Figures 2 and 3 suggest that, while ambient darkness facilitates prejudicial responses among high-BDW individuals, it may actually have the opposite effect among those low in BDW. Further research is required to determine whether this apparent reversal among low-BDW individuals is a truly meaningful effect. If it is, it will demand consideration of additional explanatory constructs (e.g., specific personality processes that contribute to-or are correlated with-low BDW) which complement those specified by intergroup vigilance theory.

Two other aspects of the results are of more immediate conceptual note. First, under conditions in which BDW and darkness exerted their 


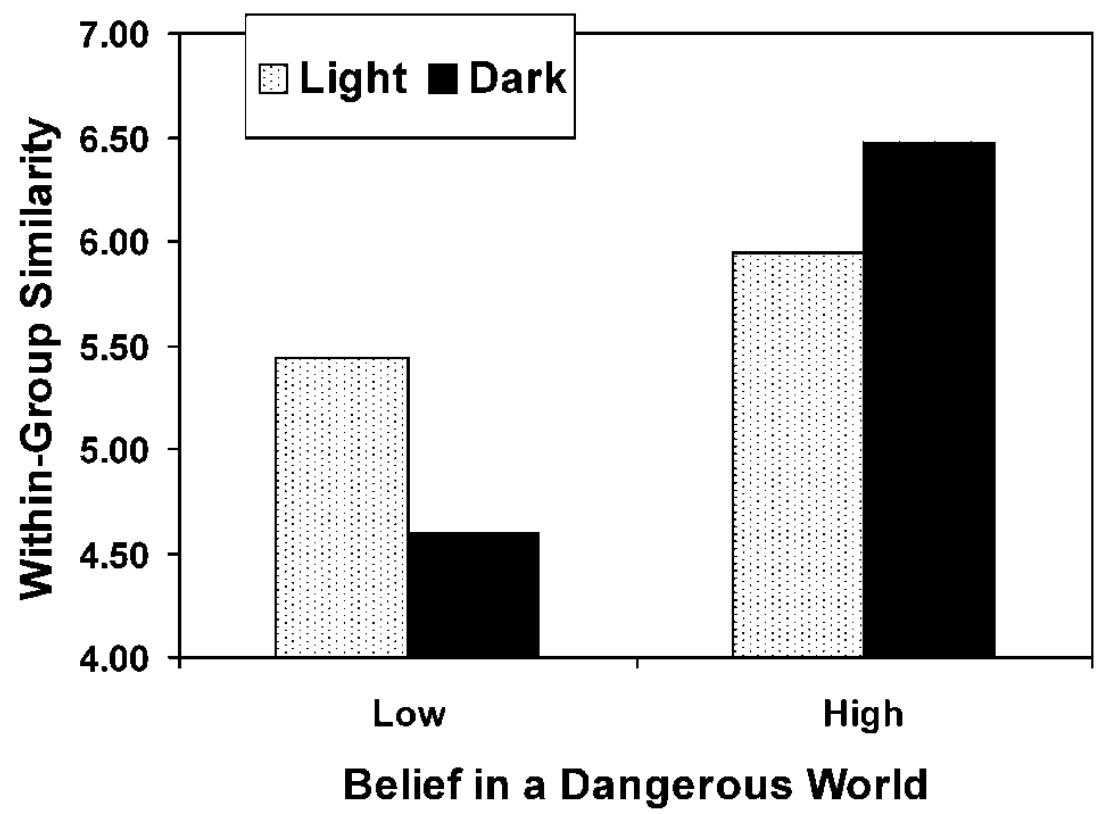

Figure 3. Interactive effect of ambient darkness and belief in a dangerous world on the extent to which members of outgroup are perceived to be similar to each other (Study 2).

effects on prejudicial beliefs, the effects were driven more by perceptions of outgroups than by perceptions of ingroups (see the means presented in Table 2). These results indicate that the effects are psychologically distinct from other processes - such as those pertaining to social identity - that influence intergroup prejudice primarily through their influence on perceptions of ingroups. Second, the effects occurred only on dangerrelevant prejudicial beliefs; no effects were observed on equally derogatory beliefs that were connotatively irrelevant to danger. These results are not only consistent with the processes specified by intergroup vigilance theory, they are inconsistent with potential alternative explanations that might be otherwise be offered by many other well-established psychological phenomena. For instance, it is possible that the sudden onset of darkness may enhance autonomic arousal, uncertainty, deindividuation, and feelings of personal anonymity; and there are conceptually distinct processes through which these constructs could lead to exaggerated expressions of prejudice. But those processes imply effects that should be observed across all evaluative domains of prejudice. They cannot provide adequate explanations for the domain-specific effects observed in these studies. 


\section{Interactive effects of ambient darkness and BDW on stereotype activation}

Further evidence supporting the predictions of intergroup vigilance theory is found in the results of two studies reported by Schaller, Park, and Mueller (2003), in which BDW and ambient darkness exerted interactive effects on the activation of ethnic stereotypes - specifically stereotypes connoting danger. In both studies, participants were non-Black university students in Canada, and the methods were designed to assess the implicit activation of stereotypes about Black people.

In one study (Schaller et al., 2003, Study 1), participants — who had earlier completed the BDW questionnaire - watched a slide show designed to make Black people salient to participants. The slide show consisted of nine photos of individual young African-American men, projected onto a blank wall of the room. Depending on experimental condition, participants were presented with these photos under conditions of either dim lighting, or near-total darkness. After the slide show, participants completed a trait-rating measure on which they rated the extent to which they perceived various traits to be part of the popular cultural stereotype of Black people. (Rather than rating their own beliefs, they rated their perceptions of others' beliefs - a method that has been used previously to infer the activation of stereotypical knowledge structures.) A subset of these traits connoted danger (e.g., criminal, untrustworthy), and was used to comprise a high danger-relevance stereotype index. Another subset of traits was also derogatory and stereotypical but was less relevant to danger (e.g., lazy, ignorant), and so was used to comprise a low danger-relevance stereotype index. Results on the high danger-relevance stereotype index revealed an interaction between BDW and ambient darkness: Stereotypes connoting danger were especially strongly activated among high-BDW individuals in the dark (see Figure 4). Effects on the low danger-relevance index were weaker.

In the other study (Schaller et al., 2003, Study 2), participants again completed the BDW measure, and were induced to think about Black people under conditions of either ambient light or ambient darkness. Stereotype activation was assessed with a computer-based reaction-time measure- the "implicit association test" (IAT; Greenwald, McGhee, \& Schwartz, 1998) that assesses differential cognitive association of social categories with semantic information. Participants completed two IAT tasks, the order of which was counterbalanced. One IAT task was designed to assess the implicit cognitive association between the social category "African" and the semantic category "danger". The other IAT task assessed the implicit association between "African" and "unpleasant". Results on the African/ danger IAT revealed the familiar interactive effects of BDW and ambient darkness; results on the African/unpleasant IAT were weaker. 


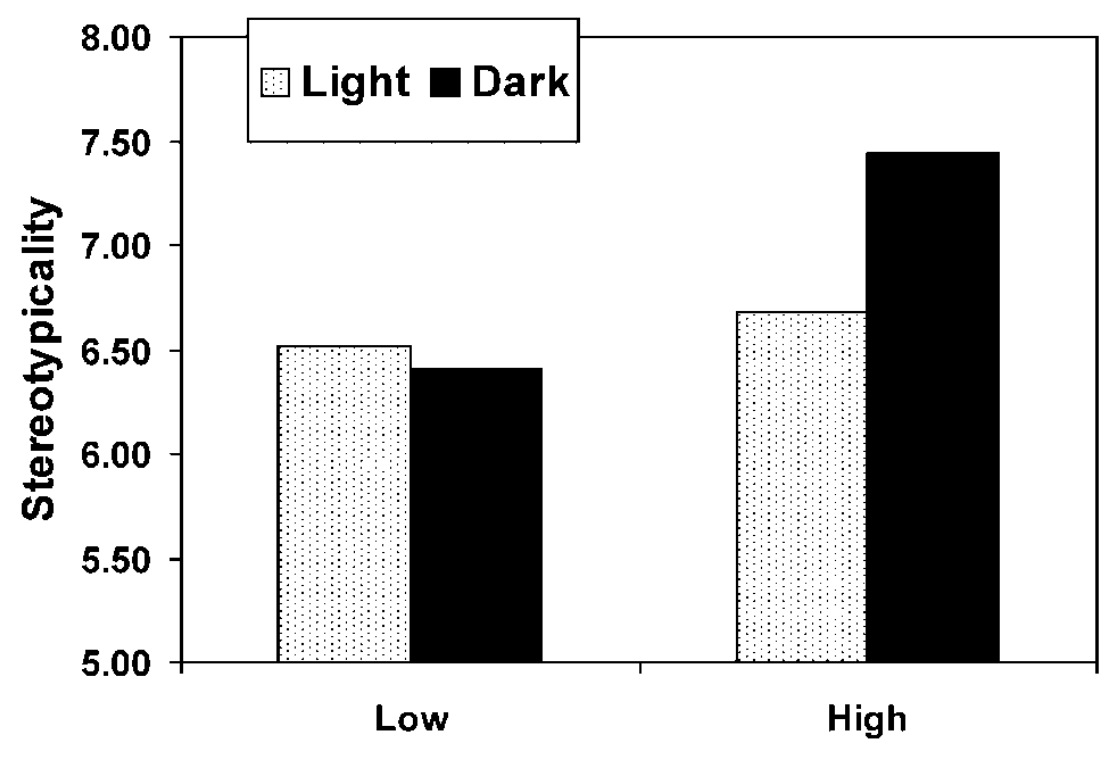

\section{Belief in a Dangerous World}

Figure 4. Interactive effect of ambient darkness and belief in a dangerous world on the extent to which danger-relevant traits are perceived to be stereotypical of Black people (Schaller et al., 2003).

These results not only further substantiate the interesting interactive effects of BDW and ambient darkness, they also indicate that these effects occur implicitly, with a minimum of cognitive effort or awareness. The automaticity of these responses is consistent with the processes specified by intergroup vigilance theory.

\section{Summary remarks}

The results of these various studies are consistent with the thesis that a specific psychological process contributing to intergroup prejudice emerged as an adaptive response to social environments in which outgroups actually posed some threat of physical injury. More interestingly, these studies reveal that this prejudice response can be triggered by contemporary cues and contexts - like ambient darkness - that heuristically connote vulnerability to danger.

Several of these studies reveal that the prejudices triggered by these variables are specific to functionally relevant domains of judgement. This domain-specificity is notable for several reasons. First, domain-specificity of exactly this sort is predicted by intergroup vigilance theory, and is a 
hallmark of many other psychological processes that have an evolutionary basis (Kenrick, Sadalla, \& Keefe, 1998; Kurzban \& Leary, 2001; Neuberg \& Cottrell, 2002). Second, it cannot be easily explained by many of the other processes that social psychologists commonly identify as the causes of intergroup prejudice - such as processes based on social identity and selfconcept. Therefore, these results signal the need to consider the role of additional prejudice processes that complement those with which we are already so familiar.

\section{PERCEIVED VULNERABILITY TO DISEASE AND ITS EFFECTS ON PREJUDICE}

Contact with other people may pose a health risk even if those people don't intend physical harm. Potential peril also lurks in the unintentional communication of disease. Thus, for sensible reasons, people prefer to avoid others who are known to be carriers of parasites and pathogens (Crandall \& Moriarty, 1995). In addition, perceived vulnerability to disease may be linked to prejudices against categories of people who are objectively non-contagious, but who have features that - at a purely heuristic levelconnote disease. These latent prejudices may themselves be responsive to background variables signalling personal vulnerable to disease.

\section{Conceptual background}

The conceptual logic underlying this disease-avoidance theory of prejudice has been summarised by Kurzban and Leary (2001), and begins with the specification that one survival problem that our ancestors faced was the avoidance of communicable pathogens and parasites. Because many of these disease-causing agents were communicated through interpersonal contact with other individuals, behavioural tendencies that facilitated the avoidance of contagious individuals would have been adaptive, as would affective reactions (e.g., disgust) and cognitive structures that motivated this sort of avoidance behaviour. Consequently, specific psychological mechanisms have evolved-and specific cultural norms may have emerged as well-to facilitate these negative psychological responses to any individual marked by features that heuristically connote disease.

The psychological mechanism linking individuals with disease is expected to be responsive to a wide range of disease-connoting features. Some of these features are the sorts of specific physical symptoms and behavioural tics that historically have been, and continue to be, correlated with the presence of contagious disease - skin lesions, coughing spasms, and so forth. It is unlikely that a disease-avoidance mechanism could have evolved to 


\section{4}

make the sort of fine distinctions that separate actual symptoms of contagious disease from a much broader category of superficially similar physical and behavioural features, many of which may be unrelated to any sort of contagious agent (Zebrowitz \& Collins, 1997). Consequently, evolved disease-avoidance mechanisms may be sensitive to a wide range of physical or behavioural features that are judged to be normatively unusual. The exact nature of these cues may vary depending on local environments.

This analysis has interesting implications for present-day prejudice and discrimination. Unusual-looking people who are objectively known not to be carriers of contagious disease may nonetheless arouse disgust, and may elicit disease-connoting cognitive and behavioural reactions. Furthermore, these reactions may be triggered most strongly under conditions in which background variables - including both chronic individual differences and temporary contexts - indicate some high personal vulnerability to contagious disease. In our recent research, we have applied this analysis to derive hypotheses about specific variables that may predict prejudices towards people with disabilities, and towards subjectively foreign ethnic outgroups.

\section{Prejudicial reactions to individuals with physical disabilities}

Individuals may appear physically unusual in a number of different ways. Some people have asymmetric features, for instance, and perceivers are perceptually sensitive to these asymmetries. Asymmetrical individuals are typically judged to be less attractive, and one explanation is that asymmetry is a cue connoting ill-health (Gangestad \& Buss, 1993; Moller, 1992). More obvious forms of physical unusualness include disfigurement and disability. There is a large literature revealing prejudicial reactions to individuals stigmatised by some sort of physical disability. These reactions tend to be defined behaviourally by avoidance and physical distancing - the same sorts of reactions directed towards individuals who actually are diseased (e.g., Snyder, Kleck, Strenta, \& Mentzer, 1979; for a review, see Park et al., 2003).

If indeed prejudicial reactions to physical disability are based, in part, on some implicit concern with disease, then these negative reactions are likely to be more pronounced among individuals who chronically feel vulnerable to disease. Park et al. (2003) report results from two studies that offer some support for this hypothesis. In both studies, participants completed an individual difference measure designed to assess "perceived vulnerability to disease" (PVD). The PVD measure contains two types of items that comprise two distinct factors. One factor reflects aversive reactions to situations in which germs are likely to be transmitted (e.g., "It really bothers me when people sneeze without covering their mouths"). The second factor 
reflects more general beliefs about personal susceptibility to contagious diseases (e.g., "In general, I think I am very susceptible to colds, flu, and other infectious diseases"). Results from one study revealed that individuals who scored more highly on the overall PVD measure were less likely to have friends with physical disabilities $(r=-.26)$.

The second study assessed implicit cognitive associations with physically disability. These implicit stereotype associations were assessed with an implicit association test (IAT) modelled after those used to assess the activation of stereotypes and attitudes bearing on ethnic groups (e.g., Greenwald et al., 1998). Participants completed two IAT tasks, the order of which was counterbalanced. One IAT task was designed to assess the implicit cognitive association between the social category "disabled" and the semantic category "disease"; the other was designed to assess the implicit association between "disabled" and "unpleasant". The results revealed that, among individuals socialised in a European culture that emphasises germs as a mode of disease transmission, scores on the germ-aversion factor of the PVD scale predicted stronger implicit associations linking disabled individuals to the connotative concept "disease" as well as stronger implicit associations linking disabled individuals to the evaluative concept "unpleasant". These effects are illustrated by means summarised in Table 3 (in which - for the sake of simple illustration-participants have been categorised depending on whether their PVD subscale scores were below or above the mean). Interestingly, no such effect was found among individuals who were socialised in an East Asian culture that traditionally emphasises rather different (not germ-based) means of contracting disease. Nor did the second PVD factor-the one assessing more general and explicit beliefs - predict these implicit associations (for details, see Park et al., 2003).

Although very preliminary, these results are generally consistent with the evolutionarily informed model of disease-based prejudice elicited by the perception of physical disability. The results from the IAT study indicate

TABLE 3

Relation between perceived vulnerability to disease (PVD - Germ Aversion Subscale) and implicit associations with physical disability (Park et al., 2003)

\begin{tabular}{llcc}
\hline & & Low PVD & High PVD \\
\hline Implicit association between & Mean & 311.42 & 473.65 \\
disability and "disease" & (SD) & $(157.15)$ & $(215.38)$ \\
Implicit association between & Mean & 233.54 & 416.77 \\
disability and "unpleasant" & (SD) & $(218.55)$ & $(144.90)$ \\
\hline
\end{tabular}

Strength of implicit association is derived from a computer-based reaction-time task, and is measured in milliseconds. (This pattern of results was found only among participants of European cultural heritage.) 
that the activation of prejudicial cognitions is based not so much on a thoughtful consideration of susceptibility to disease, but perhaps more on an affective response - probably disgust - to information connoting this form of vulnerability. This affective response may precipitate a wide range of negative cognitive associations, including associations that directly connote the implied threat (disease), as well as more diffuse evaluative associations that justify discriminatory behaviour (Haidt, 2001). These results also illustrate that, even if an underlying psychological mechanism has been sculpted by evolutionary pressures, it may still be - indeed usually is - highly responsive to social learning processes, and so may be facilitated by somewhat different sets of background variables across different cultural contexts.

\section{Prejudicial attitudes toward unfamiliar ethnic outgroups}

An evolved disease-avoidance mechanism may also play some role in prejudices against members of unfamiliar ethnic outgroups. There are several reasons why unfamiliar ethnicity may have emerged as a marker connoting threat of contagion. First, as much human epidemiological history reveals, contact with previously unknown populations brings increased risk of encountering contagious diseases for which one has no acquired immunity (Diamond, 1999). Second, individuals from non-local cultures are more likely to engage in subjectively strange customs violating local customs that help to inhibit transmission of disease (e.g., customs pertaining to hygiene, food preparation, and sexual activity). Thus, over the course of human history, avoidance and social exclusion of subjectively foreign peoples may have been functional in the avoidance of disease. Consistent with this analysis, Schiefenhövel (1997) notes that people often display disgust reactions when speaking about other ethnic groups, and Rozin, Haidt, McCauley, and Imada (1997, p. 73) suggest that "disgust in humans serves as an ethnic or outgroup marker".

If so, then - following the same line of reasoning summarised abovebackground variables connoting personal vulnerability to disease may facilitate prejudicial reactions to unfamiliar ethnic outgroups. Exactly such an effect was found across a series of studies that tested the predicted relation between individual differences in perceived vulnerability to disease (PVD) and prejudicial attitudes towards outgroups (Faulkner, Schaller, Park, \& Duncan, 2003).

Several of these studies assessed University of British Columbia students' attitudes towards potential immigrants, and examined the relation between these attitudes and PVD. In two studies, PVD predicted less favourable attitudes towards an immigrant group from Eastern Africa. One of these 
studies was particularly noteworthy because it assessed not only attitudes towards African immigrants (a population that participants perceived to engage in unfamiliar customs and habits), but also towards immigrants from Eastern Europe and Eastern Asia (populations that, given local demographics, were perceived to be more highly familiar). PVD predicted less favourable attitudes towards Africans $(r=-.38)$ but not towards the culturally familiar immigrant groups. The third study revealed that the effects of PVD are not specific to attitudes about Africans; PVD also predicted less favourable attitudes to immigrants from three additional geographical locations (Peru, Qatar, and Sri Lanka) that were perceived to be subjectively foreign.

Particularly notable is the fact that the predictive effects of PVD mirror the subjective perception of cultural unfamiliarity. Table 4 summarises means on an index - with a possible range from 1 to 9 -indicating the extent to which six different immigrant groups were judged by a separate sample of participants to have unfamiliar customs and habits. Table 4 also summarises the correlations, obtained across the two studies summarised above, between PVD and participants' attitudes favouring immigration of each group to Canada. The covariation between these two sets of numbers is extraordinarily strong.

Additional data from these studies revealed that, although PVD correlates moderately highly with BDW ( $r$ s are typically in the .3 to .4 range), the predictive effects of PVD on prejudicial reactions were largely independent of any effects of BDW. Thus, prejudice processes linked to the threat of disease seem to be psychologically distinct from prejudice processes linked to the threat of physical injury.

Prejudicial attitudes towards foreign peoples may be predicted not only by chronic worries about disease, but also by situational contexts that make

TABLE 4

Perceived cultural unfamiliarity of six immigrant groups, and the extent to which perceived vulnerability to disease (PVD) predicts attitudes supporting their immigration (Faulkner et al., 2003)

\begin{tabular}{lccc}
\hline \multirow{2}{*}{$\begin{array}{l}\text { Geographical origin } \\
\text { of immigrants }\end{array}$} & \multicolumn{2}{c}{ Cultural unfamiliarity } & $\begin{array}{c}\text { Correlation between } \\
\text { PVD and attitude }\end{array}$ \\
\cline { 2 - 3 } & Mean & $(S D)$ & .16 \\
Eastern Europe & 3.60 & $(1.40)$ & .15 \\
Eastern Asia & 4.04 & $(1.46)$ & -.38 \\
Eastern Africa & 5.84 & $(1.96)$ & -.30 \\
Peru & 5.83 & $(1.76)$ & -.36 \\
Qatar & 5.93 & $(1.74)$ & -.53 \\
Sri Lanka & 6.13 & $(1.96)$ & \\
\hline
\end{tabular}


the threat of contagious diseases temporarily salient. Faulkner et al. (2003) report results from two additional experimental studies that provide preliminary evidence consistent with this hypothesis. In both experiments, participants were randomly assigned to watch one of two different slide shows, each of which was designed to make a particular health threat salient. One slide show portrayed a threat that was irrelevant to disease; it contained a series of pictures that conveyed the ease with which physical accidents occur in everyday life. The other slide show was specifically designed to make diseases salient; it contained a series of pictures that conveyed the ease with which germs and diseases are transmitted in everyday life. Results from one study showed that - compared to the control condition in which accidents were salient - when diseases were made salient, participants were relatively less favourable towards immigrants from Nigeria (a subjectively foreign group), but not less favourable towards immigrants from Scotland (a familiar group). In the other experiment, participants indicated the percentage of a special federal budget that should be spent to recruit immigrants from each of eight countries. Immigrants from four of these countries (Nigeria, Mongolia, Brazil, and Peru) had been pre-rated as subjectively foreign; immigrants from four other countries (Scotland, Taiwan, Poland, and Iceland) had been pre-rated as subjectively familiar. Budget allocations to the four foreign locations were combined into a single index, and budget allocations to the four familiar locations were combined into a separate index. When accidents were salient, participants allocated almost equal amounts to recruit foreign and familiar immigrants; but when diseases were salient, participants allocated relatively less of the budget to recruit immigrants from foreign locations, and relatively more of the budget to recruit immigrants from familiar locations (see Figure 5).

\section{Summary remarks}

The results of these studies reveal that several quite different categories of people might be targets of prejudices that are based on some underlying concern with the transmission of disease. These prejudices are expressed more strongly by perceivers who feel more chronically vulnerable to the transmission of diseases. Preliminary evidence also indicates that these prejudices can be triggered more strongly by transient contextual cues connoting vulnerability to disease. It is also likely that these prejudices-like those based on fear of physical injury-may be responsive to complex interactions between different kinds of background variables that connote vulnerability or invulnerability to disease. These disease-based prejudices are also likely to be linked to specific affective reactions (disgust), and to imply specific kinds of cognitive and behavioural responses (especially behavioural 


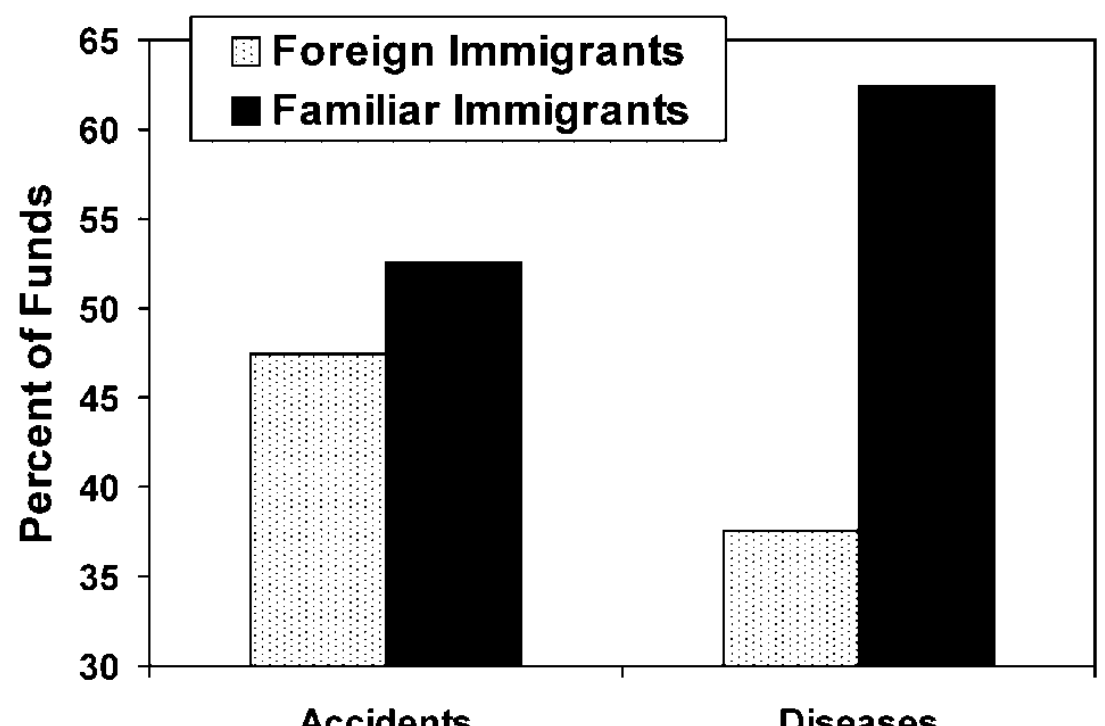

\section{Salient Threat}

Figure 5. Effect of temporarily salient threats on allocation of funds to recruit immigrants from subjectively foreign or familiar locations (Faulkner et al., 2003).

avoidance and cognitions that compel avoidance). Research exploring these implications has just begun; there are many logically implied hypotheses that remain to be tested. That fact, more than anything, reveals the heuristic hypothesis-generating value of this evolutionary approach to prejudice.

\section{BROADER IMPLICATIONS}

Any evolutionarily informed theory of psychological processes contains conceptual models at two levels of analysis. At one level of analysis, there is a model of historical events, which specifies how specific evolutionary pressures led to the emergence of specific adaptive mechanisms. The evolutionary processes specified within these historical models are exceptionally difficult to verify, and this fact surely contributes to many individuals' discomfort with evolutionary psychology (Conway \& Schaller, 2002). But the scientific utility of these historical models rests not merely on their merits as theories of evolutionary origin; it rests also on their capacity to generate, through deduction, a second conceptual model that operates at a very different level of analysis: A model of contemporary psychological events. These models should specify testable relations between psychological 
variables operating in the here-and-now. The veracity and utility of these models is what matters most within the psychological sciences.

The two evolutionarily informed theoretical frameworks reviewed above contain models of contemporary psychological events that are consistent with existing empirical data within the prejudice literature. More importantly, these models have provided a basis for the deduction of new hypotheses and the discovery of previously undocumented influences on contemporary prejudices. These conceptual models, and the results that support them, suggest some broader implications as well-which are worth considering further if we wish to understand the problems of prejudice more completely, and to address these problems more effectively.

\section{Conceptual prominence of outgroup derogation}

A defining feature of intergroup prejudice is the tendency to treat ingroups more charitably than outgroups - such as when Canadians rate their fellow Canadians more positively than they rate Iraqis. The mere fact of this bias begs a deeper question: Does the bias reflect a special benevolence towards the ingroup, a derogation of the outgroup, or both? Several theoretical perspectives on prejudice imply that the psychological "action" lies primarily in evaluations of the ingroup; careful reviews of the social psychological literature reveal that there is greater empirical evidence of ingroup favouritism than outgroup derogation (Brewer, 1979; Hewstone, Rubin, \& Willis, 2002). We might be wise, however, not to draw too quick or over-general a conclusion on the basis of these past results. The existing empirical literature may not accurately portray the full breadth of prejudice processes that operate in the real world. For a variety of reasons both conceptual and methodological, a substantial chunk of the psychological literature on stereotypes and prejudice focuses on beliefs about specific social categories that are functionally unique (e.g., men and women) or have minimal functional implication (e.g., engineers and artists). Another chunk of the literature focuses on ad-hoc "minimal" groups that are created in the laboratory; inevitably, the results of these studies reflect prejudice processes that emerge from mere categorisation in the absence of any additional functional context. The apparent absence of outgroup derogation in the empirical literature may under-represent its actual prevalence in the real world (Hewstone et al., 2002).

The evolutionary frameworks summarised here imply clearly that outgroup derogation may play a larger role in prejudice processes than is currently revealed in the social psychological literature. These theories begin with assumptions about members of specific outgroups and the formerly functional purposes served by derogatory beliefs about those groups. The 
conceptual consequences are hypotheses about contemporary acts of outgroup derogation and the circumstances under which this derogation is especially likely to occur. Under these predictable circumstances, the "action" underlying acts of prejudice may be primarily that of outgroup derogation.

The results of several of the studies reviewed above are consistent with this conceptual emphasis on outgroup derogation. The broader implication is this: By pursuing more thoroughly the implications of these and other evolutionary theories, we may rediscover the significance of outgroup derogation in the psychology of prejudice. It is an unpleasant phenomenon to focus on, but it may be necessary to a complete understanding of prejudice.

\section{Effects of threats on prejudices}

The psychology of threat is another unpleasant, but apparently necessary, focus of these evolutionary approaches to prejudice. The concept of threat has long been associated with prejudice, and has shown up in a variety of very different guises (Adorno et al., 1950; Allport, 1954; Esses, Jackson, \& Armstrong, 1999; Fein \& Spencer, 1997; Harmon-Jones, Greenberg, Solomon, \& Simon, 1996; Stephan et al., 1998). The evolutionary perspective instructs us to pay special attention to specific kinds of threats that pertain directly to bodily health. Psychological processes designed to protect against specific threats to bodily health can have important influences on prejudiceand can even influence prejudices against people that, at a rational level, pose no realistic threat at all. This conclusion is also compelled by a perusal of various forms of real-world propaganda used to justify and inflame others to engage in acts of prejudice. Suedfeld and Schaller (2002) noted that Nazi propaganda abounded with text and images that linked Jews to disease and to the threat of malicious harm. Contemporary organisations devoted to the incitement of ethnic prejudice employ similar rhetorical devices. A website maintained by one such Canadian organisation displays banners bearing slogans such as "Immigration can kill you!" and regularly features stories linking non-White immigrants to various sorts of violent crime, and to diseases ranging from tuberculosis to ebola.

Of course, one does not need an evolutionary perspective to develop a taxonomy of threats, or to assert the relation between threats and prejudices (see Stephan et al., 1998, for example). What an evolutionary perspective adds, however, is a deeper conceptual texture. This texture is useful. It helps explain why specific categories of people arouse certain forms of threat, and why specific threats arouse specific expressions of prejudice. And it helps to predict the specific circumstances in which each of those forms of prejudice is especially likely to occur. 


\section{Specificity of prejudice processes}

The concept of specificity is important to these evolutionary approaches to prejudice. This fits with a fundamental tenet underlying many inquiries within evolutionary psychology: The human mind is modular. Many different - and psychologically independent - cognitive mechanisms evolved in response to the many distinct problems bearing on survival and sexual reproduction in the ancestral past. From this perspective, the psychology of prejudice might more accurately be construed as the psychology of prejudices. It is unlikely that there is any single general-purpose process compelling us to judge all different kinds of outgroups in any sort of generally negative manner. Instead, there are many different and independent processes that, when triggered, lead us to judge specific types of others in specific types of disapproving ways.

Some of these different forms of disapproval are illustrated by the results of some of the studies reviewed above. These domain-specific results reveal a level of complexity that is often overlooked in the study of prejudice. Because prejudice so clearly implies negative affective and evaluative reactions, it is easy to forget that there are many different negative reactions that can comprise a prejudice. Recent research has begun to probe more deeply into the psychological processes underlying the distinct affective responses associated with different prejudices (e.g., Mackie, Devos, \& Smith, 2000), and these lines of inquiry are nicely complemented by an evolutionary approach to prejudice. By calling attention to different types of negative reactions and their functional implications, the evolutionary approach offers a set of useful conceptual tools to formulate questions and answers about the specific contents of specific prejudices (Neuberg \& Cottrell, 2002).

The evolutionary approach is also useful in reminding us that many prejudice processes are target-specific. We do lump people into categories, yes, and the mere fact of categorisation has psychological implications that generalise across all kinds of social categories. But not all groups and social categories are the same. (In fact, not all social categories qualify psychologically as groups.) Different types of social categories were associated with different adaptive problems - and different solutions to those problems - in ancestral environments (Bugental, 2000; Caporael, 1997; Kurzban \& Leary, 2001). Consequently, in contemporary times, different categories elicit very different prejudices, and the processes that govern prejudice against one particular category of people may be irrelevant to prejudices against other categories of people.

\section{Implications for effective interventions}

If indeed there are psychologically distinct processes that account for the different prejudices against different targets, then the tactics we devise to 
fight prejudice must be target-specific as well. Interventions designed specifically to overcome sexist attitudes are unlikely to have much impact on prejudices based on national, racial, or ethnic difference. Interventions designed specifically to overcome racism or ethnocentrism are unlikely to have much impact on prejudices against individuals with disfigurements or disabilities. If we wish to intervene effectively, it will help to attend to the specific functional origins of the many prejudices that exist.

Attention to these evolutionarily functional origins should compel us to approach intervention in a more realistic, multi-faceted manner. But it should not compel us to be pessimistic. Many prejudices may have deep evolutionary roots, but that doesn't mean we can't do something about them. An evolutionary perspective reminds us that these prejudice processes are flexible, and are responsive to the input from many different variables. If a prejudicial response to unusual-looking people is triggered by cues connoting personal vulnerability to disease, then that response may be inhibited by cues connoting invulnerability or immunity. Interventions designed to reduce individuals' real or imagined risk of contracting infectious diseases may therefore help to reduce this particular prejudice. Similarly, if a prejudice against ethnic outsiders is triggered by cues connoting vulnerability to interpersonal injury, then this prejudice might be inhibited by interventions designed to enhance feelings of safety and security. In fact, results showing exactly this effect have been reported by Mikulincer and Shaver (2001): When Israeli participants were subliminally primed with words connoting safety, they expressed less prejudice against potential immigrants.

\section{CONCLUDING REMARKS}

A common critique of theories within evolutionary psychology is that they are unnecessary - that observed relations between psychological variables can be explained without reference to the prehistoric operation of evolutionary processes. This type of critique is almost always right. It is also almost entirely irrelevant to the real value of an evolutionarily informed approach to psychology.

Observations obtained through psychological research methods refer most directly to concepts defined at a psychological level of analysis. Psychologists typically are satisfied by explanations based on processes operating strictly within this level of analysis. The plausibility of any such explanation renders additional theoretical constructs to be subjectively unnecessary, especially if those additional theoretical constructs operate - as evolutionary constructs do - at a different level of analysis entirely (Conway \& Schaller, 2002).

Explanatory necessity, however, is a very limited standard against which to judge the value of any theory (Schaller, 2002). If we limit our theoretical 
horizons to just those constructs necessary to explain the existing psychological database, then we limit our ability to address more ambitious questions about human nature and its origins. We also limit our access to conceptual tools that can lead us to new empirical discoveries. Ultimately, the primary scientific utility of any theory is not merely to explain existing empirical facts, but to generate new ones.

It is for exactly this reason that evolutionary perspectives on prejudice provide valuable scientific tools. By availing ourselves of these tools, and applying them rigorously, we may be able to chart more completely the complex workings of the many prejudices that lurk within the dark waters of the human psyche. Consequently, these tools can help us to navigate our way past these hazards, and more effectively minimise the damage that they do.

\section{REFERENCES}

Adorno, T. W., Frenkel-Brunswik, E., Levinson, D. J., \& Sanford, R. (1950). The authoritarian personality. New York: Harper.

Alexander, M. G., Brewer, M. B., \& Herrmann, R. K. (1999). Images and affect: A functional analysis of out-group stereotypes. Journal of Personality and Social Psychology, 77, 78-93.

Allport, G. W. (1954). The nature of prejudice. New York: Addison-Wesley.

Altemeyer, B. (1988). Enemies of freedom. San Francisco: Jossey-Bass.

Barkow, J., Cosmides, L., \& Tooby, J. (1992). The adapted mind: Evolutionary psychology and the generation of culture. New York: Oxford University Press.

Blascovich, J., Mendes, W. B., Hunter, S. B., Lickel, B., \& Kowai-Bell, N. (2001). Perceiver threat in social interactions with stigmatized others. Journal of Personality and Social Psychology, 80, 253-267.

Brewer, M. B. (1979). In-group bias in the minimal intergroup situation: A cognitivemotivational analysis. Psychological Bulletin, 86, 307-324.

Bugental, D. B. (2000). Acquisition of the algorithms of social life: A domain-based approach. Psychological Bulletin, 126, 187-216.

Burnstein, E., Crandall, C., \& Kitayama, S. (1994). Some neo-Darwinian decision rules for altruism: Weighing cues for inclusive fitness as a function of the biological importance of the decision. Journal of Personality and Social Psychology, 67, 773-789.

Buss, D. M. (1995). Evolutionary psychology: A new paradigm for psychological science. Psychological Inquiry, 6, 1-30.

Caporael, L. R. (1997). The evolution of truly social cognition: The core configurations model. Personality and Social Psychology Review, 1, 276-298.

Conway, L. G. III, \& Schaller, M. (2002). On the verifiability of evolutionary psychological theories: An analysis of the psychology of scientific persuasion. Personality and Social Psychology Review, 6, 152-166.

Crandall, C. S., \& Moriarty D. (1995). Physical illness stigma and social rejection. British Journal of Social Psychology, 34, 67-83.

Crawford, C., \& Krebs, D. L. (1998). Handbook of evolutionary psychology: Ideas, issues, and applications. Mahwah, NJ: Lawrence Erlbaum Associates Inc.

Cummins, D. D., \& Allen, C. (1998). The evolution of mind. New York: Oxford University Press.

Diamond, J. (1999). Guns, germs, and steel. New York: Norton. 
Esses, V. M., Jackson, L. M., \& Armstrong, T. L. (1999). Intergroup competition and attitudes toward immigrants and immigration: An instrumental model of group conflict. Journal of Social Issues, 54, 699-724.

Faulkner, J., Schaller, M., Park, J. H., \& Duncan, L. A. (2003). Evolved disease-avoidance processes and contemporary xenophobic attitudes. Unpublished manuscript, University of British Columbia, Canada.

Fein, S., \& Spencer, S. J. (1997). Prejudice as self-image maintenance: Affirming the self through derogating others. Journal of Personality and Social Psychology, 73, 31-44.

Fox, R. (1992). Prejudice and the unfinished mind: A new look at an old failing. Psychological Inquiry, 3, 137-152.

Gaertner, S. L., \& Dovidio, J. F. (2000). Reducing intergroup bias: The Common Ingroup Identity model. Philadelphia: Psychology Press.

Gaertner, S. L., Dovidio, J. F., Anastasio, P. A., Bachman, B. A., \& Rust, M. C. (1993). The Common Ingroup Identity model: Recategorization and the reduction of intergroup bias. In W. Stroebe \& M. Hewstone (Eds.), European review of social psychology (Vol. 4, pp. 1-26). Chichester UK: Wiley.

Gangestad, S. W., \& Buss, D. M. (1993). Pathogen prevalence and human mate preferences. Ethology and Sociobiology, 14, 89-96.

Gangestad, S. W., \& Simpson, J. A. (2000). The evolution of human mating: Trade-offs and strategic pluralism. Behavioral and Brain Sciences, 23, 573-644.

Garcia, J. (1981). Tilting at the paper mills of academe. American Psychologist, 36, 149-158.

Greenwald, A. G., McGhee, D. E., \& Schwartz, J. L. K. (1998). Measuring individual differences in implicit cognition: The Implicit Association Test. Journal of Personality and Social Psychology, 74, 1464-1480.

Grillon, C., Pellowski, M., Merikangas, K. R., \& Davis, M. (1997). Darkness facilitates acoustic startle reflex in humans. Biological Psychiatry, 42, 453-460.

Haidt, J. (2001). The emotional dog and its rational tail: A social intuitionist approach to moral judgment. Psychological Review, 108, 814-834.

Harmon-Jones, E., Greenberg, J., Solomon, S., \& Simon, L. (1996). The effects of mortality salience on intergroup bias between minimal groups. European Journal of Social Psychology, 26, 677-681.

Haselton, M., \& Buss, D. (2000). Error management theory: A new perspective on biases in cross-sex mind reading. Journal of Personality and Social Psychology, 78, 81-91.

Hewstone, M., Rubin, M., \& Willis, H. (2002). Intergroup bias. Annual Review of Psychology, $53,575-604$.

Judd, C. M., \& Park, B. (1988). Out-group homogeneity: Judgments of variability at the individual and group levels. Journal of Personality and Social Psychology, 54, 778-788.

Kenrick, D. T., Li, N. P., \& Butner, J. (2003). Dynamical evolutionary psychology: Individual decision rules and emergent social norms. Psychological Review, 110, 3-28.

Kenrick, D. T., Sadalla, E. K., \& Keefe. R. C. (1998). Evolutionary cognitive psychology: The missing heart of modern cognitive science. In C. Crawford \& D. L. Krebs (Eds.), Handbook of evolutionary psychology (pp. 485-514). Mahwah NJ: Lawrence Erlbaum Associates Inc.

Ketelaar, T., \& Ellis, B. J. (2000). Are evolutionary explanations unfalsifiable? Evolutionary psychology and the Lakatosian philosophy of science. Psychological Inquiry, 11, 1-21.

Kingsolver, B. (1995). High tide in Tucson: Essays from now or never. New York: HarperCollins.

Krebs, D. L., \& Denton, K. (1997). Social illusions and self-deception: The evolution of biases in person perception. In J. A. Simpson \& D. T. Kenrick (Eds.), Evolutionary social psychology (pp. 21 -47). Mahwah, NJ: Lawrence Erlbaum Associates Inc.

Kurzban, R., \& Leary, M. R. (2001). Evolutionary origins of stigmatization: The functions of social exclusion. Psychological Bulletin, 127, 187-208. 
Mackie, D. M., Devos, T., \& Smith, E. R. (2000). Intergroup emotions: Explaining offensive action tendencies in an intergroup context. Journal of Personality and Social Psychology, 79, $602-616$.

Marr, D. (1982). Vision. San Francisco: Freeman.

Mikulincer, M., \& Shaver, P. R. (2001). Attachment theory and intergroup bias: Evidence that priming the secure base schema attenuates negative reactions to out-groups. Journal of Personality and Social Psychology, 81, 97-115.

Moller, A. P. (1992). Parasites differentially increase the degree of fluctuating asymmetry in secondary sexual characteristics. Journal of Evolutionary Biology, 5, 691-700.

Mullen, B., Brown, R., \& Smith, C. (1992). Ingroup bias as a function of salience, relevance, and status: An integration. European Journal of Social Psychology, 22, 103-122.

Murphy, D. (2003). Adaptationism and psychological explanation. In S. J. Scher \& F. Rauscher (Eds.), Evolutionary psychology: Alternative approaches (pp. 161-184). Boston: Kluwer Academic Publishers.

Neuberg, S. L., \& Cottrell, C. A. (2002). Intergroup emotions: A biocultural approach. In D. M. Mackie \& E. R. Smith (Eds.), From prejudice to intergroup relations: Differentiated reactions to social groups (pp. 265-283). Philadelphia: Psychology Press.

Neuberg, S. L., Smith, D. M., \& Asher, T. (2000). Why people stigmatize: Toward a biocultural framework. In T. Heatherton, R. Kleck, J. G. Hull, \& M. Hebl (Eds.), The social psychology of stigma (pp. 31-61). New York: Guilford Press.

Öhman, A., \& Mineka, S. (2001). Fear, phobia, and preparedness: Toward an evolved module of fear and fear learning. Psychological Review, 108, 483-522.

Park, J. H., Faulkner, J., \& Schaller, M. (2003). Evolved disease-avoidance processes and contemporary anti-social behaviour: Prejudicial attitudes and avoidance of people with disabilities. Journal of Nonverbal Behavior, 27, 65-87.

Phelps, E. A., O’Conner, K. J., Cunningham, W. A., Funayama, E. S., Gatenby, J. C., Gore, J. C. et al. (2000). Performance on indirect measures of race evaluation predicts amygdala activation. Journal of Cognitive Neuroscience, 12, 729-738.

Pinker, S. (1997). How the mind works. New York: Norton.

Pratto, F., Sidanius, J., \& Stallworth, L. M. (1993). Sexual selection and the sexual and ethnic basis of social hierarchy. In L. Ellis (Ed.), Social stratification and socioeconomic inequality: A comparative biosocial analysis (pp. 111-137). Westport CT: Praeger.

Rothbart, M., \& Park, B. (1986). On the confirmability and disconfirmability of trait concepts. Journal of Personality and Social Psychology, 50, 131-142.

Rothgerber, H. (1997). External intergroup threat as an antecedent to perceptions of in-group and out-group homogeneity. Journal of Personality and Social Psychology, 73, $1206-1212$.

Rozin, P., Haidt, J., McCauley, C., \& Imada, S. (1997). Disgust: Preadaptation and the cultural evolution of food-based emotion. In H. MacBeth (Ed.), Food preferences and taste (pp. $65-$ 82). Providence, RI: Berghahn.

Schaller, M. (2002). Any theory can be useful theory, even if it gets on our nerves. Personality and Social Psychology Review, 6, 199-203.

Schaller, M. (2003). Ancestral environments and motivated social perception: Goal-like blasts from the evolutionary past. In S. J. Spencer, S. Fein, M. P. Zanna, \& J. M. Olson (Eds.), Motivated social perception: The Ontario Symposium (pp. 215-231). Mahwah NJ: Lawrence Erlbaum Associates Inc.

Schaller, M., Asp, C. H., Rosell, M. C., \& Heim, S. J. (1996). Training in statistical reasoning inhibits the formation of erroneous group stereotypes. Personality and Social Psychology Bulletin, 22, 829-844.

Schaller, M., \& Crandall, C. S. (2003). The psychological foundations of culture. Mahwah NJ Lawrence: Erlbaum Associates Inc. 
Schaller, M., Park, J. H., \& Mueller, A. (2003). Fear of the dark: Interactive effects of beliefs about danger and ambient darkness on ethnic stereotypes. Personality and Social Psychology Bulletin, 29, 637-649.

Scher, S. J., \& Rauscher, F. (2002). Evolutionary psychology: Alternative approaches. Dordrecht: Kluwer.

Schiefenhövel, W. (1997). Good tastes and bad tastes: Preferences and aversions as biological principles. In H. MacBeth (Ed.), Food preferences and taste (pp. 55-64). Providence, RI: Berghahn.

Simpson, J. A., \& Kenrick, D. T. (1997). Evolutionary social psychology. Mahwah NJ: Lawrence Erlbaum Associates Inc.

Snyder, M. L., Kleck, R. E., Strenta, A., \& Mentzer, S. J. (1979). Avoidance of the handicapped: An attributional ambiguity analysis. Journal of Personality and Social Psychology, 37, 2297-2306.

Stephan, W. G., Diaz-Loving, R., \& Duran, A. (2000). Integrated threat theory and intercultural attitudes: Mexico and the United States. Journal of Cross-Cultural Psychology, $31,240-249$.

Stephan, W. G., Ybarra, O., Martinez, C. M., Schwarzwald, J., \& Tur-Kaspa, M. (1998). Prejudice toward immigrants to Spain and Israel. Journal of Cross-Cultural Psychology, 29, $559-576$.

Suedfeld, P., \& Schaller, M. (2002). Authoritarianism and the Holocaust: Some cognitive and affective implications. In L. S. Newman \& R. Erber (Eds.), What social psychology can tell us about the Holocaust: Understanding perpetrator behaviour (pp. 68-90) Oxford: Oxford University Press.

Wright, S. C., Aron, A., McLaughlin-Volpe, T., \& Ropp, S. A. (1997). The extended contact effect: Knowledge of cross-group friendships and prejudice. Journal of Personality and Social Psychology, 73, 73-90.

Zebrowitz, L. A., \& Collins, M. A. (1997). Accurate social perception at zero acquaintance: The affordances of a Gibsonian approach. Personality and Social Psychology Review, 1, 204223. 